\title{
Dois Monólogos Não Fazem um Diálogo: jovens e ensino médio
}

\begin{abstract}
Carmem Zeli Vargas Gil Fernando Seffner

'Universidade Federal do Rio Grande do Sul (UFRGS), Porto Alegre/RS - Brasil

RESUMO - Dois Monólogos Não Fazem um Diálogo: jovens e ensino médio. Pautado em alguns estudos de pesquisadores que têm produzido conhecimento sobre as conexões entre culturas juvenis e escola, o texto aponta diferentes contornos que ampliam a visão tradicional da juventude como tempo de problemas e dos jovens como indivíduos na contramão do sistema escolar. Ao mesmo tempo, o texto propõe questões que ampliam o debate em torno do ensino médio para pensar temas relacionados às juventudes, compreendendo que os jovens possuem saberes gestados em diferentes espaços educativos, sujeitos a múltiplas pedagogias culturais, o que implica atenção em pensar conteúdos e métodos de ensino. As ideias aqui reunidas pretendem instigar discussões entre jovens e educadores, buscando ressignificar os sentidos atribuídos ao Ensino Médio.

Palavras-chave: Jovens. Ensino Médio. Participação. Desigualdades.
\end{abstract}

ABSTRACT - Two Monologues Do Not Make a Dialogue: youth and secondary education. Based on some studies about the connections between youth culture and school, the text questions the traditional view of youth as troubled times and young people as individuals against the school system. At the same time, the text poses questions that broaden the debate concerning the secondary education to consider issues related to youth cultures. The young people possess knowledge generated in different educational scopes, subject to multiple cultural pedagogies, which demands attention to thinking about contents and teaching methods. The ideas here gathered are intended to instigate debates among young people and educators, seeking to reframe the meanings assigned to the Secondary Education. Keywords: Youth. Secondary Education. Participation. Inequalities.

Educação \& Realidade, Porto Alegre, v. 41, n. 1, p. 175-192, jan./mar. 2016. 


\section{Juventude, Juventudes, Escola, Escolas}

Com franqueza, estava arrependido de ter vindo. Agora que ficava preso, ardia por andar lá fora, e recapitulava o campo e o morro, pensava nos outros meninos vadios, o Chico Telha, o Américo, o Carlos das Escadinhas, a fina flor do bairro e do gênero humano. Para cúmulo de desespero, vi através das vidraças da escola, no claro azul do céu, por cima do morro do Livramento, um papagaio de papel, alto e largo, preso de uma corda imensa, que bojava no ar, uma coisa soberba. E eu na escola, sentado, pernas unidas, com o livro de leitura e a gramática nos joelhos (Assis, 2007, p. 327).

Contos de Escola nos inspira a refletir sobre os sentidos da escola para os jovens. Talvez diferente do imaginário do autor, a escola hoje se constitua como um lugar mais aberto e menos disciplinador da diversidade de sujeitos que passam a frequentá-la. Mudaram os livros, os mestres, a disposição das mesas e cadeiras, os tempos, as tarefas e os sentidos se reconfiguraram. Impõe-se a pergunta: é possível fazer da escola pública destinada aos jovens dos setores populares, espaço cultural e educativo de vivência intergeracional? Pode a escola promover o diálogo entre jovens e educadores possibilitando ver o mundo não através das vidraças, mas compreender o mundo que está dentro da escola? Muito se debate hoje em dia sobre o ensino médio. Mesmo com tantos debates, corremos o risco de ter monólogos, ao invés de diálogos. Nossa aposta neste texto é propor algumas reflexões sobre as juventudes e o ensino médio, tomando como referência propostas de reestruturação do ensino médio e o tema da participação juvenil, tramando ideias para transformar os monólogos em diálogos mais efetivos.

Para construir ferramentas de análise das propostas que circulam, elegemos, neste texto, dois critérios. O primeiro trata da conexão entre jovens e participação social. Em termos efetivos, podemos observar se as propostas para o ensino médio privilegiam a formação de jovens com engajamento na vida social e política, aliado ao ensino dos conteúdos científicos. Educar para a participação política não é algo que apenas se ensina, mas algo que se pratica na escola. Isso envolve currículos e gestão escolar que valorizem as culturas juvenis, dialoguem com elas e tenham abertura à participação dos jovens na gestão do processo educativo. O segundo critério diz respeito ao enfrentamento da desigualdade na sociedade brasileira.

Os jovens, a cada dia, chegam às escolas e configuram novos desafios aos educadores e gestores. Em 2013, 83,3\% dos jovens de 15 a 17 anos estavam na escola (IBGE/Pnad. Todos Pela Educação). A Emenda Constitucional no 59/2009 definiu o Ensino Médio como uma etapa obrigatória da Educação Básica no Brasil. Com duração de três anos para a faixa etária de 15 a 17 anos, em oferta de cursos médio regular, 
médio regular integrado à educação profissional, normal/magistério, além do ensino médio na modalidade educação de jovens e adultos. Cabe destacar também que a meta 3 do Plano Nacional de Educação ${ }^{1}$, estabelece a universalização do ensino médio. Ora, a expansão do ensino médio ampliou a presença do contingente juvenil, historicamente fora da escola, embora ainda longe da universalização. O resultado da Pesquisa Nacional por Amostra de Domicílio (Pnad) 2013 aponta que apenas 54,3\% dos jovens até 19 anos cursam o ensino médio até o seu final. Houve uma melhoria nestes índices: 46,6\% em 2007, 51,6\% em 2009 e 53,4\% em 2011, embora persista a dificuldade dos jovens concluírem o ensino médio na idade certa.

A distorção idade-série e a evasão escolar são dois grandes desafios do Ensino Médio brasileiro que necessitam ser enfrentados para dar conta do que preconiza o PNE, que indica a universalização da educação até 2016 para jovens de 15 a 17 anos e do aumento de $30 \%$ das matrículas no ensino médio até 2024.

Figura 1 - Porcentagem de jovens de 15 a 17 anos matriculados no Ensino Médio - Taxa líquida de matrícula

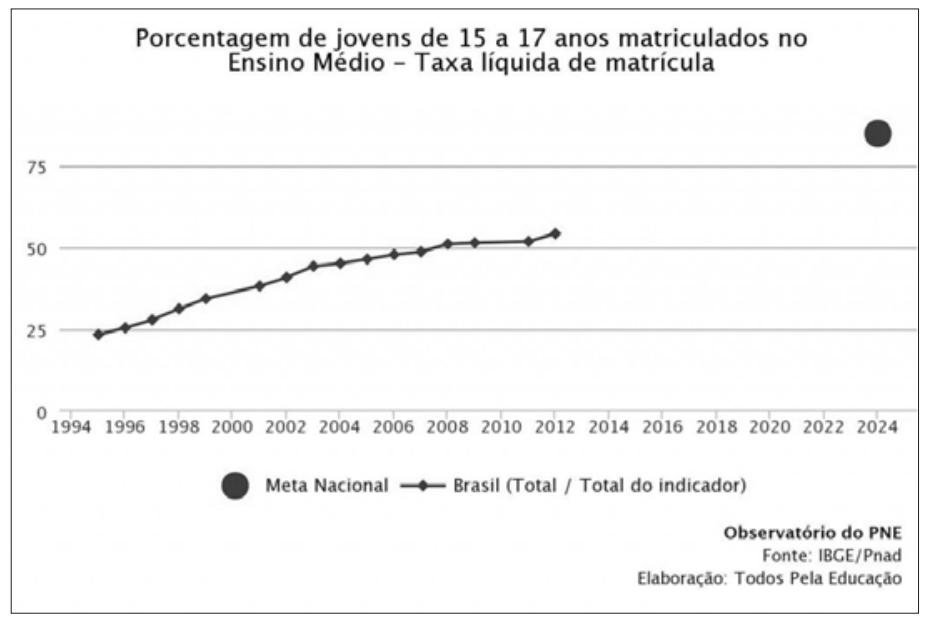

Outro ponto deste debate diz respeito ao que entendemos por juventude como uma categoria construída. Para o ocidente, a juventude caracteriza-se como grupo etário distinto, com papel social definido, que começa a se colocar no período da sociedade industrial. Talvez se possa dizer que, se James Watt foi o inventor da máquina a vapor em 1765, Rousseau foi o inventor do jovem, com Emílio, ou, Da Educação, (2004), publicado originalmente em 1762. Emílio é a obra que vai produzir, em nível teórico, a concepção moderna de infância e adolescência - matriz do que será depois juventude. É Rousseau quem vai falar da adolescência como um segundo nascimento. Uma época, segundo ele, especialmente turbulenta, que deve ser constantemente vigiada. 
Esta concepção consolida-se no século XIX e, junto a ela, um interesse novo pela juventude, tempo também de turbulência, caracterizada por um excesso de paixão irracional que deveria ser vigiado e enclausurado (Gil, 2011).

Perceber a juventude como um momento da vida que marcaria a saída da infância até o ingresso no mundo adulto, vivido de forma homogênea, é ignorar as condições histórico-culturais dos integrantes desta categoria. Como anuncia Levi e Schmitt (1996),

Essa 'época da vida' não pode ser definida com clareza por quantificações demográficas, nem por definições de tipo jurídicas, e é por isso que nos parece substancialmente inútil tentar identificar e estabelecer, como fizeram outros, limites muito nítidos (Levi; Schmitt, 1996, p. 19).

Pais (1993) diz que a juventude é uma categoria socialmente construída. Portanto, sujeita a modificar-se ao longo do tempo. Assim, em uma mirada histórica podemos dizer que, nos diferentes contextos históricos e culturais, os jovens já foram a geração cética (Alemanha pós 1945); a geração abatida (Espanha pós-guerra civil); a geração sofrida (Itália, na II Guerra) para referir-se a comportamentos decorrentes das sequelas das guerras que produziram desesperança. Porém, o crescimento econômico da Europa dos anos 1960, propagando valores de consumo, possibilitou o aparecimento de uma cultura juvenil como categoria autônoma, convertendo-se em idade da moda. Ao mesmo tempo, emergiu a imagem do rebelde sem causa. Nos bairros de Londres, em 1976, após a explosão dos Sex Pistols, afirmou-se um novo estilo com os punks.

Em 1985, a UNESCO declara o Ano Internacional da Juventude ${ }^{2}$, sinalizando que as coisas não iam muito bem. A desocupação juvenil, a ruína das ideologias, o questionamento sobre o sentido da escola produziam uma atitude desencantada que Michel Maffesoli definiu como tempos das tribos (Maffesoli, 1998). Ou seja, tempos que congregavam formas de sociabilidade que se manifestavam no desejo de estar-junto à toa, muito diferente das sociabilidades modernas. Para este autor as tribos seriam as agregações às quais as pessoas se unem, por afinidade e voluntariamente, para compartilhar coisas em comum.

No Brasil, acompanhando os movimentos mundiais, os jovens já foram, homogeneamente, definidos como rebeldes, geração paz e amor, ousados e participativos, geração perdida, gangues, cara-pintada e, neste momento, parece que a diversidade ganha mais visibilidade, dificultando que um grupo assuma a representação de todos. Hoje, para as fronteiras enfatizam as passagens, para as hierarquias firmam as hibridizações, para as oposições ressaltam as conexões. Viver a juventude, como lembra Feixa (2004), já não é - como no complexo de Tarzan transitar da natureza à cultura, nem tampouco - como no complexo de Peter $\operatorname{Pan}^{3}$ - resistir à vida adulta, mas experimentar o destino incerto 
- como no complexo do Replicante, de Blade Runner, que se rebela porque não tem memória do passado. Para Feixa, existe nesse fenômeno uma grande contradição, pois os jovens querem ser adultos enquanto os adultos querem ser jovens. Obviamente que os jovens alcançarão a vida adulta, mas os adultos não poderão retornar à juventude. Este paradoxo se aproxima da história do filme Blade Runner ${ }^{4}$. Tal como os replicantes que são perseguidos pelos caçadores, os jovens são protagonistas de todos os desejos e todos os males (Gil, 2012).

Serão os jovens deste início de século replicantes? Uma geração @ que coloca o sentido da vida no presente; sem memória, não tem consciência das possibilidades de projetar o futuro? Programados para utilizar as tecnologias, estão mais preparados para as mudanças e, talvez, para enfrentar o futuro sem preconceitos? Com o fim das grandes utopias, são agora protagonistas de revoltas episódicas; têm o mundo ao seu alcance, mas não são senhores de seus destinos.

Tal como em Blade Runner, os adultos vacilam entre o encanto pela juventude e a necessidade de exterminar tudo que ameaça a ordem e a norma. O resultado de tudo isto é, como propõe Feixa (2004), um modelo híbrido e ambivalente de juventude, marcado pela dependência econômica, falta de espaço de responsabilização e um crescente amadurecimento intelectual que se expressa no acesso às novas tecnologias.

Feixa (2004) define juventude como um Jano de dois rostos: uma ameaça de presentes obscuros e uma promessa de futuros radiantes. São como anjos que nos deslumbram e monstros que nos assustam. $\mathrm{O}$ mito de Jano é interpretado geralmente como símbolo do passado e do futuro. Entre o tempo que já não é, e o tempo que ainda não foi, encontra-se um terceiro rosto de Jano, invisível, que olha o presente.

Assim, se a juventude foi vista como uma etapa de transição marcada por crises e mudanças ou, depois, nos anos 1980, como categoria cultural protagonista do mercado, hoje se torna uma etapa permanente, o período mais duradouro da vida. Como entrecruzar tais reflexões com os desafios do ensino médio hoje no Brasil, é pergunta que se impõe para a continuidade do texto.

\section{Reformas no Ensino Médio: cada cabeça uma sentença}

O ensino brasileiro vive, desde a proclamação da Constituição de 1988, um processo crescente de preocupações por parte de governantes, sociedade civil, movimentos populares, associações religiosas, empresariado, agências internacionais, comunidades de pais e alunos e associações profissionais de docentes, e isto para ficar apenas nos atores sociais majoritários. Vale lembrar que foi na Constituição de 1988 que se conseguiu escrever, pela primeira vez na história pátria, que a educação fundamental é obrigatória, ou seja, o comparecimento dos alunos à escola é obrigatório, e a oferta de vagas por parte das mantenedoras (estado, união, municípios) é também obrigatória. Para grande número 
de países, essa obrigatoriedade veio junto com a proclamação da república, no século XIX. No caso brasileiro, ela demorou praticamente cem anos para se instalar entre nós. Assim que instalada, passou a produzir efeitos. Próximo do ano 2000, o Brasil já ostentava índices de frequência do alunado à escola de ensino fundamental superiores a 95\%, em qualquer região do País (Oliveira, 2007).

Com o aumento de concluintes do ensino fundamental, passou a existir uma pressão sobre o ensino médio. $\mathrm{O}$ ensino médio não foi definido na Constituição de 1988 como de matrícula obrigatória, mas a Emenda Constitucional no 59, de 11 de novembro de 2009, indica o ano de 2016 para a conclusão deste processo de obrigatoriedade ${ }^{5}$. Há um conjunto enorme de desafios para que tal processo se efetive. Para o diálogo com os valores e práticas das culturas juvenis, interessa de perto saber se a escola de ensino médio é atraente ao aluno, de modo que ele possa se vincular a ela completando a escolarização no tempo adequado, com bom aproveitamento. Para tanto, existe um conjunto de programas de financiamento, mas estes apresentam problemas:

A estagnação dos indicadores de fluxo escolar do ensino fundamental, acompanhada de ligeira tendência de deterioração a partir da $5^{\mathrm{a}}$ série (aumento das taxas de repetência e evasão), sugere, porém, que os efeitos iniciais positivos do FUNDEF vêm perdendo fôlego, indicando claramente os limites de uma estrutura de incentivos baseada exclusivamente no quantitativo de matrículas. A garantia de repasse de recursos com base no número de alunos atendidos, independentemente do desempenho de indicadores de qualidade, parece ter gerado acomodação dos agentes responsáveis pelas redes de ensino fundamental público (Goulart; Sampaio; Nespoli, s/d, p. 4).

A discussão feita pelos autores, bem como em Oliveira (2007), mostra os limites da simples inclusão de alunos na escola pública brasileira, sem garantia de mecanismos de efetiva aprendizagem e progressão: progressivamente, os alunos perdem o interesse pela escola, se evadem, ou passam a reprovar constantemente, frequentando a escola talvez pela sociabilidade, mas sem aprendizagens significativas. Podemos considerar que o simples acesso não se traduz em efetiva democratização do ensino médio. Insistimos na aposta deste texto: a vinculação do aluno de ensino médio à escola acontece se as marcas de sua cultura juvenil são consideradas, e se há um estímulo a sua participação social na escola. Isso não significa transformar a escola de ensino médio em uma sociedade recreativa para jovens, significa sim que a escola deve fazer um esforço para dialogar com as culturas juvenis, tratando o aluno de ensino médio como alguém que é portador de ideias, proposições acerca do mundo, visões políticas e gostos culturais próprios. Mas a tarefa não é apenas da escola e do professor, ela também precisa estar presente no desenho das políticas públicas em educação, o que, de certa forma, vem ocorrendo de forma tímida. 
A sociedade em que vivemos é dita frequentemente como sendo uma sociedade do conhecimento ou uma sociedade da informação ou uma sociedade da aprendizagem (Coutinho; Lisboa, 2011). Mesmo com o desgaste dessas categorias, pela banalização de seu uso no senso comum, elas guardam evidente conexão com o acesso e permanência na escolarização formal. Por este e outros tantos motivos, todos os países se movem no sentido de ofertar uma escolaridade de pelo menos doze anos aos jovens, em geral pensada como nove anos de escolaridade fundamental, mais três anos de ensino médio, o que no Brasil se conhece com o nome de educação básica, mas que ainda estamos longe de atingir em plenitude:

O advento da Emenda Constitucional no 59/2009, que prescreveu a obrigatoriedade do ensino médio a partir de 2016 a todos os indivíduos (na idade própria ou não), torna a questão ainda mais relevante, uma vez que os indicadores oficiais recentes evidenciam um longo caminho a ser percorrido com vista à efetivação de tal ditame constitucional. No caso, vale ressaltar, tomados os dados de 2008, que: • Dos indivíduos na faixa etária de 15 a 17 anos (10,28 milhões), apenas 5,18 milhões estavam matriculados no ensino médio (TML de 50,4\%); • Tendo em vista que, no mesmo ano, 8,6 milhões dos indivíduos de 15 a 17 anos eram estudantes, há um número significativo de jovens e adolescentes que deveriam estar cursando o ensino médio que ainda não conseguiram vencer as barreiras do ensino fundamental; • Mais de 1,6 milhão de pessoas em idade apropriada para o ensino médio sequer estão matriculados na escola - em qualquer nível ou modalidade (Lima, 2011, p. 282).

As estatísticas trazidas aqui, bem como algumas percepções que avançamos, não deixam margem para a dificuldade da tarefa de assegurar a todos os jovens oportunidades de acesso e permanência no ensino médio na escola pública brasileira. Propostas demasiadamente ousadas terminam por ser aventureiras, e correm o risco de não se efetivar, com a possibilidade de que professores e escolas sejam acusados pelo não cumprimento das metas, como tem sido comum no Brasil, com evidente acentuação desse comportamento nos últimos anos. Dessa forma, se por um lado devemos lutar para a democratização do ensino médio aos jovens, por outro temos que saber analisar as propostas existentes com elementos sólidos.

Temos também um conjunto de atores sociais nessa luta pela ampliação do ensino médio, que articula as políticas públicas de educação com o discurso do desenvolvimento estratégico ${ }^{6}$. Ou seja, o crescimento do País, sua presença econômica cada vez mais notável na arena internacional, seu peso político perceptível no cenário global, trouxeram consigo outro conjunto de preocupações para a educação nacional. Um forte componente produtivista se incorporou ao discurso educacional, tendo como objetivo produzir sujeitos para as necessidades específicas 
do crescimento econômico, conforme discutido em Freitas (2013; 2012; 2011), com impactos visíveis nas avaliações nacionais de professores e de alunos.

Neste contexto, surgem propostas em âmbito estadual e nacional para ressignificar o ensino médio. Para construir ferramentas de análise das propostas que circulam, elegemos neste texto dois critérios. $\mathrm{O}$ primeiro trata da conexão entre jovens e participação, que será desenvolvida no próximo tópico. O segundo critério diz respeito ao enfrentamento da desigualdade na sociedade brasileira. De modo claro, o ensino médio necessita ser a oportunidade para que os jovens estudem e compreendam a formação da sociedade brasileira, nos seus mais diversos aspectos, e enfrentem o tema da histórica desigualdade.

Para discutir a questão da desigualdade brasileira e os modos de inserção do tema na proposta do ensino médio, partimos da de um rápido olhar sobre a desigualdade econômica, para depois pensar outros modos de desigualdade presentes na sociedade:

O Brasil é um importante caso para se estudar a pobreza, não somente porque possui uma grande parte da população pobre da América Latina, mas também porque apresenta um grande potencial para erradicar a pobreza. $\mathrm{O}$ relativamente alto PIB per capita brasileiro, combinado com o alto grau de desigualdade da renda, gera condições favoráveis para o desenho de políticas redistributivas. Esse potencial é exemplificado pela alta sensibilidade dos índices de desigualdade e pobreza, e mudanças em certos instrumentos de política - por exemplo, mudanças no salário mínimo e nas taxas de inflação (Neri; Soares, 2002, p. 78).

Os autores refletem sobre a série histórica de dados que vai dos anos 1970 até o ano 2000, marcada pela persistente alta desigualdade econômica, fruto da elevada concentração de renda, o que permite explicar a pobreza de grande parte da população brasileira não por ser o Brasil um país pobre - ou seja, país sem recursos suficientes para erradicar a pobreza, como é o caso de muitos outros - mas por ser um país de riqueza concentrada - país rico, com população pobre. A persistência da desigualdade atravessa pelo menos dois momentos políticos bem diversos da história brasileira, a saber, ditadura militar (1964-1985) e retomada democrática (1985 em diante, para a série histórica considerada pelos autores, finalizando no ano 2000, considerada a data do artigo citado). Para a série histórica analisada podemos até afirmar que em praticamente metade do tempo (15 anos) vivemos em uma ditadura, com desigualdade, alta concentração de renda e grande parte da população na pobreza, e praticamente a segunda metade do tempo (outros 15 anos) vivemos em um período de retomada democrática, eleições livres, e com a mesma estrutura de desigualdade. Tal situação já permitiu afirmar que "[...] na visão de Roberto Martins no final dos anos 1990, presidente do Ipea durante, a trajetória da desigualdade de renda brasileira de 1970 a 2000 lembrava o cardiograma de um morto" (IPEA, 2012, 
p. 3). Mas a consolidação do regime democrático permitiu o paulatino enfrentamento da situação de desigualdade econômica:

\begin{abstract}
De acordo com a PNAD, a desigualdade de renda no Brasil vem caindo continuamente desde 2001. Entre 2001 e 2011, a renda per capita dos $10 \%$ mais ricos aumentou $16,6 \% \mathrm{em}$ termos acumulados, enquanto a renda dos mais pobres cresceu notáveis $91,2 \%$ no período. Ou seja, a do décimo mais pobre cresceu $550 \%$ mais rápido que a dos $10 \%$ mais ricos. Os ganhos de renda obtidos aumentam paulatinamente, na medida em que caminhamos do topo para a base da distribuição de renda (IPEA, 2012, p. 6).
\end{abstract}

Associamos essa mudança positiva no cenário da desigualdade econômica brasileira com a noção de densidade democrática (Santos; Avritzer, 2002), que nos permite pensar a vida em uma democracia para além das eleições, e permite pensar soluções democráticas para outras desigualdades, para além da desigualdade econômica. É dentro deste quadro que se pode pensar a escola em conexão com as culturas juvenis. Avançamos aqui alguns marcadores econômicos do período 2001-2011 com impactos nos jovens que frequentam a escola de ensino médio:

\begin{abstract}
No caso das pessoas que vivem em famílias chefiadas por analfabetos, a renda sobe $88,6 \%$, vis-à-vis um decréscimo de $11,1 \%$ daquelas cujas pessoas de referência possuem 12 ou mais anos de estudo completos. A renda do Nordeste sobe $72,8 \%$, contra $45,8 \%$ do Sudeste. Similarmente, a renda cresceu mais nas áreas rurais pobres, $85,5 \%$, contra 40,5\% nas metrópoles e 57,5\% nas demais cidades. [...] A renda daqueles que se identificam como pretos e pardos sobe $66,3 \%$ e $85,5 \%$, respectivamente, contra $47,6 \%$ dos brancos. A renda das crianças de 0 a 4 anos sobe $61 \%$, contra $47,6 \%$ daqueles de 55 a 59 anos (IPEA, 2012, p. 7).
\end{abstract}

Os alunos que frequentam o ensino médio - ou que estão habilitados a frequentar o ensino médio, mas por razões diversas ainda não o fazem - trazem algumas das marcas percebidas nos indicadores econômicos acima: podem ser filhos de famílias com pais analfabetos; podem ser pretos, pardos ou brancos; podem estar situados em famílias com irmãos ainda crianças; podem residir em áreas rurais, metrópoles ou pequenas cidades. Partimos da desigualdade econômica, considerada em geral a mais importante das desigualdades, mas alargamos nosso olhar para os jovens aptos ao ensino médio. As culturas juvenis são marcadas por outras diferenças, que podem gerar desigualdades, relacionadas ou não à renda. Os jovens do ensino médio têm diferenças de pertencimento religioso, e o pertencimento religioso tem desempenhado notavelmente um papel importante na geração de desigualdades. Isso se verifica, por exemplo, na hostilidade crescente entre os integrantes de algumas religiões, gerando casos de intolerância religiosa, como são aqueles que envolvem os evangélicos pentecostais em relação às religiões afro-brasileiras, historicamente perseguidas.

Educação \& Realidade, Porto Alegre, v. 41, n. 1, p. 175-192, jan./mar. 2016. 183 
Os jovens do ensino médio têm diferenças de simpatia partidária, e isso pode gerar também situações de desigualdade, em que alguns não se sintam em condições seguras de expressar suas opiniões políticas, pois também nesse quesito temos uma distribuição de poder na imprensa brasileira que compromete a densidade democrática desejável. Os alunos que frequentam o ensino médio têm diferenças de gênero, a saber, são rapazes ou moças. Essa diferença pode facilmente se converter em desigualdade, se não atentarmos para os números da violência contra a mulher, para os casos de estupro, se a escola ficar alheia aos movimentos sociais que hoje em dia reivindicam, de muitos modos diferentes, a equidade de gênero, e consideram os direitos das mulheres como parte dos direitos humanos. No quesito sexualidade há enormes diferenças a atravessar as juventudes, em particular pelo aumento expressivo da visibilidade de gays, lésbicas, travestis e transexuais e pela sua inclusão na escola pública brasileira.

O Brasil tem atualmente não apenas programas para lidar com o tema na escola, como é o caso do Brasil sem Homofobia ${ }^{7}$, como tem legislação acerca do uso do nome social em muitos municípios, estados, bem como em órgãos federais ${ }^{8}$. Os jovens brasileiros na idade de cursar o ensino médio têm diferenças de cor da pele, marcador social que no caso brasileiro é claramente produtor de desigualdade, por conta do racismo ainda presente entre nós. Em relação a esse tópico, também o Brasil tem produzido legislações nos últimos anos, como a Lei no 10.639, de 9 de janeiro de 2003; e a Lei no 11.645, de 10 de março de 2008, que dispõem sobre a obrigatoriedade de ensino da História e Cultura Afro-Brasileira e Indígena. Vale também lembrar que a adoção do regime de cotas para o ingresso no ensino superior trouxe enorme impacto na escola pública brasileira, em particular no ensino médio. Há muitos outros marcadores da diferença presentes entre os jovens, que podem com facilidade se transformar em marcadores de desigualdade. De toda forma, concluímos esta seção com um dado otimista em relação ao processo histórico de luta contra a desigualdade:

O Brasil atingiu em 2011, pela PNAD, seu menor nível de desigualdade de renda desde os registros nacionais iniciados em 1960. Na verdade, a desigualdade no Brasil permanece entre as 15 maiores do mundo, e levaria pelo menos 20 anos no atual ritmo de crescimento para atingir níveis dos Estados Unidos, que não são uma sociedade igualitária. Porém, isso significa que existem consideráveis reservas de crescimento pró-pobre, que só começaram a ser exploradas na década passada (IPEA, 2012, p. 8).

Na continuidade do texto, reúnem-se alguns estudos de pesquisadores que têm produzido conhecimento sobre o tema da participação juvenil e educação, apontando a necessidade de a escola reconhecer os diferentes contornos das juventudes e, a partir disso, reconhecê-los como sujeitos atuantes no cenário público.

184 Educação \& Realidade, Porto Alegre, v. 41, n. 1, p. 175-192, jan./mar. 2016. 


\section{Jovens e Participação ${ }^{9}$ : um debate necessário para o ensino médio}

Por que o tema da participação é necessário no debate sobre o ensino médio e a escola? Reconhecer que os jovens estão reinventando o mundo da participação social com diferentes formas de ocupação do espaço público, ajuda a construir novos entendimentos sobre os veredictos conclusivos impostos aos jovens deste tempo. Talvez o exercício de outro olhar para as mobilizações da juventude faça emergir a criatividade que reinventa o mundo do trabalho, as ações solidárias, a indignação ética presente em alguns grupos juvenis e a emergência de temas ecológicos nas ações e projetos de grupos juvenis. Tal perspectiva amplia a legitimidade dos jovens diante dos adultos, o que, talvez, aproxime jovens e educadores. Se quisermos, como educadores, compreendê-los, precisamos conhecê-los indo além das predefinições dos jovens como quem não sabe, não tem futuro, consumista, alienado ou rebelde. Ao contrário, reconhecer que cada um traz para a escola suas experiências de vida com interesses diversos. Como, então, acolher, compreender e potencializar suas experiências na construção de projetos de vida?

Indicamos, nestes escritos, a necessidade da escola e seus atores reconhecerem que a mobilização coletiva assume formas que escapam às modalidades tradicionais. Assim, é necessário romper com as comparações geracionais do tipo no meu tempo os jovens eram participativos. As pesquisas sobre as juventudes têm-se ampliado, nos últimos anos, para diversas produções no campo das ciências sociais sobre os movimentos juvenis, as identidades dos jovens e as formas de participação social e política dos mesmos. Pais (1993); Feixa (2006); Margulis (1998); Levi e Schmitt (1996); Peralva (1997); Foracchi (1972); Novaes (2004; 2005); Sposito (2007), dentre outras. Observa-se que a participação juvenil na contemporaneidade difere do envolvimento dos movimentos de décadas anteriores e, via de regra, como sugere Serna (1997), aponta para: 1) a novidade das causas de mobilização; 2) a priorização da ação imediata; 3) a localização do indivíduo na organização ou movimento; e 4) a ênfase na horizontalidade dos processos de coordenação.

Inegavelmente, as causas das lutas juvenis se multiplicaram e produziram distinções dos conflitos de décadas passadas, que tinham como protagonistas os movimentos estudantis, organizações de bairro e sindicatos, entre outros. Hoje as lutas se pulverizam e os jovens se agregam em grupos que atuam em esferas diferenciadas. Além dos movimentos tradicionais, vinculados aos espaços escolares, ao escotismo, aos partidos políticos e às ações com motivação religiosa, entre outros, os jovens têm-se agregado na defesa das questões ambientais, dos direitos das minorias étnicas, dos direitos sexuais, dos direitos humanos, em diversos coletivos, vinculados ou não a espaços institucionais. Os jovens priorizam os pequenos espaços da vida cotidiana como trincheiras para impulsionar a transformação global (Reguillo, 2003).

Educação \& Realidade, Porto Alegre, v. 41, n. 1, p. 175-192, jan./mar. 2016. 
Em relação ao Brasil, que cenário se apresenta aos atores juvenis quando, a partir da década de 1990, novos atores entram em cena? Não somente o estudante, o operário, o sindicalista assumem lugar de destaque no espaço público. Alguns atores desaparecem, outros se formam, consolidam-se processos de institucionalização e de modernização, mas nascem também novos problemas e se revelam novos espaços de conflitos (Melucci, 2001). As mudanças político-institucionais que se dão a partir da década de 1980, com o fim do regime militar, muitas por pressões da sociedade civil, resultam na criação de novos espaços públicos de interação e negociação, ampliando a representatividade dos setores organizados para atuarem junto aos órgãos públicos.

Nessa década, a Constituição Brasileira de 1988 redefine o papel do governo federal, que passa a assumir a coordenação das políticas públicas sociais, enquanto aos municípios cabe a maior parte da responsabilidade de sua execução. Esse formato federativo previu a transferência de diversas atribuições, responsabilidades e recursos da instância federal para os níveis estadual e municipal de governos, bem como a autonomia de estados e municípios para definirem a organização e a gestão de suas ações.

Constitui-se, a partir daí, uma agenda de reformas tendo como meta a descentralização, que se tornou pauta importante nos debates políticos do País, considerando a centralização de poder na União que a Constituição de 1988 buscou romper. Os trabalhos de Dagnino (2002) e Souza $(2001 ; 2005)$ revelam os limites e as possibilidades da chamada descentralização no Brasil. O certo é que esta ganhou ares de democratização, tendo como meta a participação e o controle social das ações do governo. O debate girava também em torno dos direitos sociais e da ampliação da cidadania. Nesse cenário, o poder local foi adquirindo visibilidade para empreender formas inovadoras de gestão, oportunizando a participação de diversos atores sociais.

A década de 1990 foi, então, marcada pelo conflito entre a expectativa de implementação de políticas públicas que concretizassem os direitos conquistados e assegurados em lei, a partir da luta dos setores progressistas da sociedade que pediam a regulamentação dos direitos sociais inscritos na Constituição de 1988. Foram regulamentadas as áreas da criança e do adolescente, da seguridade social, da saúde, da assistência social, da educação e da previdência social (Carvalho, 2004). Também as questões juvenis ganham espaço na agenda pública, representadas por políticas setoriais ou por categorias de população. São as chamadas políticas focalizadas, uma vez que os destinatários se definem a partir da necessidade, pobreza ou risco.

Tendo em vista a diversidade de formas de organização e de práticas políticas das juventudes, Melucci (2001) diz que, nas últimas décadas, os jovens são atores centrais nas mobilizações coletivas. Isso é perceptível tanto em ações empreendidas por jovens como na participação de jovens em mobilizações que envolvem outras categorias so- 
ciais. O reconhecimento da juventude como grupo social estratégico para ações coletivas e dos jovens como sujeitos de direitos fez emergir o movimento juvenil na construção de uma nova relação entre Estado e sociedade.

\section{Para Pensar Conexões entre Jovens e Ensino Médio}

O conceito que dá suporte a pensar conexões entre culturas juvenis e escola, entre jovens e ensino médio, é o de cultura escolar. Por cultura escolar estamos entendendo um conjunto de disposições e registros simbólicos, que constitui esse lugar chamado escola, e permite que ele seja de imediato reconhecido, mesmo quando se observam regiões diferentes e até mesmo com certa variação de tempos históricos. A cultura escolar é um artefato histórico, que se corporifica em rituais específicos da vida escolar, no mobiliário e na distribuição arquitetônica das construções, no linguajar que é tido como pedagogicamente adequado para este espaço, no regime de horários, no currículo explicitamente praticado, no regimento disciplinar que delimita o que pode e o que não pode ser feito, nos modos de lazer adequados, na distribuição por gênero das expectativas (o que é próprio de meninos, o que é próprio de meninas), nos meios e modos de avaliação das condutas e das aprendizagens, incluídas aí as eventuais punições e os reforços de comportamentos positivos, e em um sem número de outras disposições, que dão corpo a esta instituição que de imediato reconhecemos, a escola.

Observar a cultura escolar é examinar normas, finalidades da escola e da educação escolar em uma sociedade, pensar os meios e modos da profissionalização docente, observar o que se ensina, como se ensina, e de que modos se dá a seleção dos conteúdos. A cultura escolar pode ser pensada como mais ou menos próxima da cultura familiar, e este é um tema importante. Se pensada como continuação da cultura familiar, se perde a noção de escola como espaço público e de negociação das diferenças, e se transforma a professora em uma continuação da figura materna. Se pensada de modo autônomo da cultura familiar, a escola ganha importância como espaço público, laboratório do exercício da vida pública para as novas gerações, e marcada pelas liberdades laicas. A cultura escolar pode ser pensada como em total sintonia com a cultura profissional, o que em geral oportuniza que as empresas e os mercados colonizem a instituição escolar, exagerando seu caráter propedêutico. Excessivo afastamento das preocupações do mundo do trabalho provoca que a imagem da escola como instituição pareça distanciada do mundo "[...] o fetiche da cultura escolar isolada de outras culturas (universitária, industrial, não escolar, tradições populares). A escola se vê reduzida a uma ilha fora da História" (Silva; Fonseca, 2010, p. 15).

De toda forma, “[...] esta cultura escolar não pode ser estudada sem a análise precisa das relações conflituosas ou pacíficas que ela mantém, 
a cada período de sua história, com o conjunto das culturas que lhe são contemporâneas: cultura religiosa, cultura política ou cultura popular" (Julia, 2001, p. 10). Em sintonia com esses pressupostos, afirmamos que a cultura escolar tem que manter um importante diálogo com as culturas juvenis, e isso deve ser feito articulado com o propósito de desenvolver o interesse pela participação dos jovens na vida política e social. Como já afirmamos acima, não é algo que apenas se estude, é algo que a escola pratica, no modo como se organiza. Isso se articula com o esforço de pensar o ensino médio na perspectiva dos jovens que frequentam esta etapa escolar.

Buscamos neste texto gerar pontes de diálogo entre jovens e educadores, entre culturas juvenis e escola, tomando como referência o tema da participação juvenil e a condição desigual que marca tanto a sociedade quanto a juventude brasileira. Neste sentido, trouxemos elementos para propor uma mirada reflexiva para as propostas de reformulação do ensino médio operando com estes dois critérios de análise. É possível transformar os quesitos em questões, para dirigir aos documentos das políticas públicas e aos próprios gestores. Tais propostas instigam o reconhecimento do jovem como sujeito criativo e participativo? Tais propostas reconhecem a tarefa de reduzir as desigualdades que atuam na sociedade brasileira? Tais propostas desenham não apenas projetos de estudo de temas, mas pensam também na organização democrática da escola? Tais propostas reconhecem que a democratização do acesso e permanência ao ensino médio não é apenas conteúdo de estudo, mas também conjunto de práticas de gestão escolar? Tais propostas levam em conta a necessidade da escola de turno integral, onde os jovens terão espaços e tempos institucionais para propor temas de estudo e vivência, ao lado das disciplinas e projetos interdisciplinares propostos pelos professores? Tais propostas viabilizam recursos para a ampliação de vagas e acolhida dos jovens nas escolas de ensino médio, com recursos tecnológicos adequados?

Armados com estas perguntas, e muitas outras que podem ser feitas seguindo a ótica que aqui adotamos, respeitamos os jovens desta geração, que vivem uma experiência cultural distinta de outras, socializados com as tecnologias digitais, inventivos em suas formas de participação política, desafiando o Estado, a família e a escola, em especial, a de ensino médio a reinventar formas de viver, minimamente, a condição juvenil. Consideramos que os docentes e os gestores que praticam 0 respeito pelas culturas juvenis têm grandes chances de serem também respeitados por elas, o que possibilita construir uma escola acolhedora aos jovens, e que cumpre com seus propósitos de educação científica e socialização para a participação política.

Recebido em 27 de maio de 2015 Aprovado em 25 de novembro 2015 


\section{Notas}

1 Meta 3: Universalizar, até 2016, o atendimento escolar para toda a população de 15 a 17 anos ( $100 \%$ na escola) e elevar, até o final do período de vigência deste PNE, a taxa líquida de matrículas no ensino médio de 59,5\% em 2013para $85 \%$.

2 Com a Resolução n. 4.014/1985, a ONU declara o Ano Internacional da Juventude: Participação, desenvolvimento e paz.

3 A expressão foi usada por Dan Kiley (psicólogo americano) em 1983, em seu livro The Peter Pan Syndrome: Men Who Have Never Grown Up.

4 Filme lançado em 1982, com o título em português "Blade Runner - O Caçador de Androides", dirigido por Ridley Scott. O filme explora a relação humanos e robôs, especialmente em questões éticas e morais, e se detém também em apresentar situações acerca da memória e da duração da vida, que para o caso dos replicantes (ou androides) é curta e sempre com o vigor da juventude.

5 A Emenda pode ser consultada na íntegra em: <http://www.planalto.gov.br/ ccivil_03/constituicao/Emendas/Emc/emc59.htm> e a localização dos parágrafos por ela modificados na Constituição Federal acerca deste tema podem ser vistos em: <http://www.planalto.gov.br/ccivil_03/constituicao/Constituicao. htm\#art208i>. Acesso em : 19 de maio de 2015.

6 No caso brasileiro, são evidentes nos últimos anos as conexões entre educação e desenvolvimento estratégico, e entre educação e redução da desigualdade. O tema ultrapassa amplamente o universo acadêmico, e tem forte incidência em jornais, revistas e programas de televisão, bem como no discurso de anúncio das políticas públicas de educação. Para dar uma ideia da amplitude, recomendamos a leitura da Revista Exame, Edição 1052, ano 47, n. 20, de 30 de outubro de 2013, com matéria de capa intitulada "Hora da virada na educação?", e com grande número de dados estatísticos. Também a edição n. 428 da revista América Economia Brasil, de outubro 2013, com matéria de capa sobre o tema da desigualdade no Brasil, apontando os investimentos em educação como um das saídas para atingir patamares elevados de igualdade no País.

$7 \mathrm{O}$ acesso ao documento oficial do programa pode ser feito em: <http://www. biblioteca.presidencia.gov.br/publicacoes-oficiais-1/catalogo/orgao-essenciais/secretaria-de-direitos-humanos/brasil-sem-homofobia-programa-decombate-a-violencia-e-a-discriminacao-contra-lgbt-e-de-promocao-dacidadania-homossexual/view> . Acesso em: 19 de maio de 2015.

8 São inúmeras as decisões recentes autorizando o uso do nome social em locais dos mais diversos. Como exemplo de decisão que traz impactos nos sistemas de ensino temos a Resolução no 12 , de 16 de janeiro de 2016, do CNCD/LGBT da Secretaria Especial de Direitos Humanos da Presidência da República, disponível em: <http://www.sdh.gov.br/sobre/participacao-social/cncd-lgbt/ resolucoes/resolucao-012>. Acesso em: 19 de maio de 2015.

9 Parte das reflexões deste tópico estão discutidos de modo mais denso em Gil (2012). 


\section{Referências}

ASSIS, Machado de. Conto de Escola. In: GLEDSON, John (Sel.). 50 Contos de Machado de Assis. São Paulo: Companhia das Letras, 2007. P. 326-333.

BLADE Runner. Direção: Ridley Scott. Intérpretes: Harrison Ford; Rutger Hauer; Sean Young; Edward James Olmos e outros. Roteiro: Hampton Fancher e David Peoples. Los Angeles: Warner Brothers, 1982. 1 DVD (117 min.).

BRASIL. Constituição da República Federativa do Brasil de 1988. Diário Oficial [da República Federativa do Brasil], Brasília, DF, 191-A de 05/10/1988, P.1.

BRASIL. Emenda Constitucional n 59, de 11 de novembro de 2009. Diário Oficial da União, Brasília, DF, 12 nov. 2009. P. 8.

BRASIL. Secretaria de Direitos Humanos. Resolução no 12, de 16 de janeiro de 2015, do CNCD/LGBT da Secretaria Especial de Direitos Humanos da Presidência da República. Brasília, 16 jan. 2015. Disponível em: <http://www.sdh.gov.br/ sobre/participacao-social/cncd-lgbt/resolucoes/resolucao-012>. Acesso em: 19 de maio de 2015.

CARVALHO, Giane Alves. A Corda Bamba: violência juvenil e políticas públicas. 2004. 242 f. Dissertação (Mestrado em Sociologia Política) - Programa de Pós-Graduação em Sociologia Política, Universidade Federal de Santa Catarina, 2004.

CONSELHO Nacional de Combate à Discriminação. Brasil Sem Homofobia: Programa de combate à violência e à discriminação contra GLTB e promoção da cidadania homossexual. Brasília: Ministério da Saúde, 2004. Disponível em: <http://www.biblioteca.presidencia.gov.br/publicacoes-oficiais-1/catalogo/ orgao-essenciais/secretaria-de-direitos-humanos/brasil-sem-homofobia-programa-de-combate-a-violencia-e-a-discriminacao-contra-lgbt-e-de-promocao-da-cidadania-homossexual/view>. Acesso em: 19 maio 2015.

COUTINHO, Clara; LISBÔA, Eliana. Sociedade da Informação, do Conhecimento e da Aprendizagem: desafios para a educação no século XXI. Revista de Educação, Universidade do Minho, v. XVIII, n. 1, p. 5-22, 2011. Disponível em: <http://repositorium.sdum.uminho.pt/bitstream/1822/14854/1/Revista_Educ a\%C3\%A7\%C3\%A3o,VolXVIII,n\%C2\%BA1_5-22.pdf>. Acesso em: 19 maio 2015.

DAGNINO, Evelina (Org.). Sociedade Civil e Espaços Públicos no Brasil. São Paulo: Paz e Terra/Unicamp, 2002.

DESIGUALDADE no Brasil. Revista América Economia Brasil, São Paulo, n. 428, out. 2013.

FEIXA, Carles Pàmpols. De Jóvenes, Bandas y Tribus. Barcelona: Editorial Ariel, 2006.

FEIXA, Carles Pàmpols. A Construção Histórica da Juventude. In: CACCIA-BAVA, Augusto; PÀMPOLS, Carles Feixa; CANGAS, Yanko Gonzáles. Jovens na América. Latina. São Paulo: Escrituras Editora, 2004. P. 183-255.

FORACCHI, Marialice Mencarini. A Juventude na Sociedade Moderna. São Paulo: EDUSP, 1972.

FREITAS, Luiz Carlos de. A Qualidade da Escola e os Profissionais da Educação: confiança nas relações ou cultura da auditoria. In: CUNHA, Célio; SOUZA, José Vieira de; SILVA, Maria Abádia da (Org.). Políticas Públicas de Educação na América Latina: lições aprendidas e desafios. Campinas: Autores Associados, 2011. P. 279-302.

190 Educação \& Realidade, Porto Alegre, v. 41, n. 1, p. 175-192, jan./mar. 2016. 
FREITAS, Luiz Carlos de. Os Reformadores Empresariais da Educação: da desmoralização do magistério à destruição do sistema público de educação. Educação \& Sociedade, Campinas, v. 33, p. 379-404, 2012.

FREITAS, Luiz Carlos de. Políticas de Responsabilização: entre a falta de evidência e a ética. Cadernos de Pesquisa, Fundação Carlos Chagas, São Paulo, v. 43, n. 148, p. 348-365, 2013.

GIL, Carmem Zeli de Vargas. Participação Juvenil e Escola: os jovens estão fora de cena? Última Década, Viña del Mar, v. 37, p. 87-109, 2012.

GIL. Carmem Zeli de Vargas. Jovens e juventudes: consensos e desafios. Educação, Santa Maria, v. 36, n. 1, p. 25-42, jan./abr. 2011.

GOULART, Linda Taranto; SAMPAIO, Carlos Eduardo Moreno; NESPOLI, Vanessa. O Desafio da Universalização do Ensino Médio. Documento INEP/MEC. Disponível em: <http://www.fundaj.gov.br/geral/educacao_foco/universalizacao.pdf>. s/d. Acesso em: 19 maio 2015.

HORA da virada na educação? Revista Exame, São Paulo, ano 47, ed. 1052, n. 20, 30 out. 2013.

IBGE. Instituto Brasileiro de Geografia e Estatística. Pesquisa Nacional por Amostra de Domicílios (PNAD). Rio de Janeiro, 2013.

IPEA - Instituto de Pesquisa Econômica Aplicada. A Década Inclusiva (20012011): Desigualdade, Pobreza e Políticas de Renda. Comunicados do IPEA, n. 155 de 25 de setembro de 2012. Disponível em: <http://ipea.gov.br/portal/index. php?option=com_content\&view=article\&id=15611 >. Acesso em: 19 maio 2015.

JULIA, Dominique. A Cultura Escolar como Objeto Histórico. Revista Brasileira de História da Educação, Maringá, n. 1, p. 9-43, jan./jun. 2001.

LEVI, Giovanni; SCHMITT, Jean-Claude. História dos Jovens, v. 1 (da Antiguidade à era moderna). Tradução: Cláudio Marcondes, Nilson Moulin e Paulo Neves. São Paulo: Companhia das Letras, 1996.

LIMA, Leonardo Claver Amorim. Da Universalização do Ensino Fundamental ao Desafio de Democratizar o Ensino Médio em 2016: o que evidenciam as estatísticas? Revista Brasileira de Estudos Pedagógicos, Brasília, v. 92, n. 231, p. 268-284, maio/ago. 2011.

MAFFESOLI, Michel. O Tempo das Tribos: o declínio do individualismo nas sociedades de massa. Rio de Janeiro, Forense Universitária, 1998.

MARGULIS, Mario. Viviendo a Toda: jóvenes, territorios culturales y nuevas sensibilidades. Santafé de Bogotá: Siglo del Hombre Editores, Departamento de Investigaciones Universidad Central, 1998.

MELUCCI, Alberto. A Invenção do Presente: movimentos sociais nas sociedades complexas. Tradução: Maria do Carmo Alves do Bom Fim. Rio de Janeiro: Vozes. 2001.

NERI, Marcelo; SOARES, Wagner. Desigualdade Social e Saúde no Brasil. Cadernos Saúde Pública, Rio de Janeiro, n. 18 (Suplemento), p. 77-87, 2002

NOVAES, Regina R.; VITAL, Cristina. A Juventude de Hoje: (re)invenções da participação social. In: THOMPSON, Andrés A. (Org.). Associando-se à Juventude para Construir o Futuro. Revisão e tradução do espanhol Fernando Legoni. São Paulo: Peirópolis, 2005. P. 109-147.

NOVAES, Regina R.; VANUCHI, Paulo (Org.). Juventude e Sociedade: Trabalho, Educação, Cultura e Participação. São Paulo: Ed. Fundação Perseu Abramo, 2004.

Educação \& Realidade, Porto Alegre, v. 41, n. 1, p. 175-192, jan./mar. 2016. 
OLIVEIRA, Romualdo Portela de. Da Universalização do Ensino Fundamental ao Desafio da Qualidade: uma análise histórica. Educação e Sociedade, Campinas, v. 28, n. 100 - Especial, p. 661-690, out. 2007.

PAIS, José Machado. Culturas Juvenis. Lisboa: Imprensa Nacional Casa da Moeda, 1993.

PERALVA, Angelina. O Jovem como Modelo Cultural. Revista Brasileira de Educação, Rio de Janeiro, n. 5 e 6, p. 15-24, maio/ago. set./dez. 1997.

REGUILLO, Rossana. Ciudadanias Juveniles en America Latina. Última Década, Viña del Mar, n. 19, CIDPA, nov. 2003.

ROUSSEAU, Jean-Jacques. Emílio, ou, Da Educação. 3. ed. Tradução de Roberto Leal Ferreira. São Paulo: Martins Fontes, 2004.

SANTOS, Boaventura de Sousa; AVRITZER, Leonardo. Para Ampliar o Cânone Democrático. In: SANTOS, Boaventura de Sousa (Org.). Democratizar a Democracia: os caminhos da democracia participativa. Rio de Janeiro: Civilização Brasileira, 2002. P. 39-82.

SERNA, Leslíe. Globalización y Participación Juvenil. JOVENes, Revista de Estudios sobre Juventud, Mexico, Ano 1, n. 5, p. 42-57, jul./dic. 1997.

SILVA, Marcos Antônio da; FONSECA, Selva Guimarães. Ensino de História hoje: errâncias, conquistas e perdas. Revista Brasileira de História, São Paulo, v. 31, n. 60, p. 13-33, 2010.

SOUZA, Celina. Sistema Brasileiro de Governança Local: inovações institucionais e sustentabilidade. In: LUBAMBO, Catia; COELHO, Denilson Bandeira; MELO, Marcos André. Desenho Institucional e Participação Política: exigências no Brasil Contemporâneo. Petrópolis: Vozes, 2005. P. 108-131.

SOUZA, Celina. Federalismo e Descentralização na Constituição de 1988: processo decisório, conflitos e alianças. Dados - Revista de Ciências Sociais, Rio de Janeiro, v. 44, n. 3, p. 513-560, 2001.

SPOSITO, Marilia Pontes (Org.). Espaços públicos e Tempos Juvenil: um estudo de ações do poder público em cidades de regiões metropolitanas brasileiras. São Paulo: Global, 2007.

Carmem Zeli Vargas Gil é licenciada em História e doutora em Educação (UFRGS 2009). Docente e orientadora do Mestrado Profissional em Ensino de História do IFCH e Professora da Faculdade de Educação da Universidade Federal do Rio Grande do Sul, Porto Alegre, RS, Brasil. Bolsista CAPES, processo 6187/14-5.

E-mail: carmemz.gil@gmail.com

Fernando Seffner é licenciado em História e doutor em Educação (UFRGS 2003). Docente e orientador junto ao PPGEDU/UFRGS e ao Mestrado Profissional em Ensino de História. Integrante do LISTHE Laboratório de Ensino de História e Educação. Este artigo é um dos produtos do período de pós-doutorado do autor, financiado pelo CNPq, processo 201042/2014-2.

E-mail: fernandoseffner@gmail.com 